\title{
Pure alexia and right hemiachromatopsia in posterior dementia
}

\author{
L Freedman, L Costa
}

\begin{abstract}
A 66 year old, right handed woman presented with pure alexia and right hemiachromatopsia (PARH) in the context of a posterior dementia. PARH was accompanied by prosopagnosia, 2-D object agnosia, and environmental agnosia. Visual fields were normal to confrontation testing. The pathological anatomy of PARH involves circumscribed damage to the lingual and fusiform gyri and paraventricular white matter of the left occipital cortex, two contiguous cortical regions functionally specialised for processing colour and word form information, respectively.
\end{abstract}

Pure alexia and right hemiachromatopsia (PARH) reflect disorders of reading and contralateral colour perception, respectively. ${ }^{1}$ Both conditions result from damage to the left occipital lobe usually secondary to infarction of the posterior cerebral artery. ${ }^{1}$ The cortical areas responsible for processing colour and letter information are functionally distinct yet anatomically contiguous being localised to the lingual and fusiform gyri and paraventricular white matter of the left occipital cortex. ${ }^{1}$ PARH are clinically dissociable, ${ }^{12}$ and rarely occur simultaneously in the absence of a right scotoma or superior quadrantanopia. ${ }^{34} \mathrm{We}$ describe a patient with PARH and intact visual fields (VF) which occurred in the context of a posterior dementia.

\section{Case report}

A 66 year old, right handed woman was referred for neurobehavioural testing because of a three year history of progressive visual anomia, alexia, and prosopagnosia. Serial neurological examinations revealed normal findings with intact visual fields. Serial CT of the brain showed no focal lesions, hydrocephalus, or posterior atrophy. An EEG revealed diffuse slowing without focal features. Laboratory investigations were negative and medical history was remarkable for atrial fibrillation.

The patient was seen for neurobehavioural testing in November 1983. Intellectual evaluation with the WAIS-R indicated severe compromise in visuospatial ability (PIQ $=69)$ with relatively spared verbal skills (VIQ $=91$ ). There were severe impairments in constructional praxis, matching of unfamiliar faces, visuospatial reasoning, and topographic orientation. She was severely prosopagnosic, being unable to recognise famous and familiar faces, as well as her reflection in a mirror. A visual object agnosia was present confined to two-dimensional stimuli. Verbal fluency, tactile naming, auditory comprehension, and oral spelling were intact. Verbal memory was mildly compromised on measures of repetition learning and visual recognition memory was intact. The summary memory quotient (MQ) was within the psychometric normal range (MQ = 96).

Examination of reading and colour perception indexed a pure alexia and right hemiachromatopsia. The alexia was characterised by a letter-by-letter decoding strategy complimented by visual paralexic errors. Letters of similar visual structure were frequently misread. Colour perception was evaluated by having the patient name, match, and discriminate coloured tokens ( blue, green, yellow, red) on free-field and half-field presentations. The patient demonstrated intact colour perception on all test parameters on free-field and left-field presentations. In contrast, there was severe compromise $(0 \%)$ in naming, matching, and discrimination of all colours on right-field presentation.

The patient was lost to follow up although correspondence with her physician several years later revealed relentless clinical deterioration with development of dementia characterised by a global visual and tactile agnosia and severe visuospatial compromise.

\section{Discussion}

Our patient exhibited classical signs of PARH indexed by letter-by-letter reading, visual paralexias, and a defective ability to name, match, and discriminate colours presented to the right visual field. Colour perception was intact in the left visual field and PARH was observed in the absence of any aphasia, colour anomia, or colour agnosia.

While pure alexia and right achromatopsia can occur in isolation, they are usually accompanied by other visual disorders. These can include object and colour anomia, ${ }^{13}$ colour agnosia, ${ }^{3}$ object agnosia, ${ }^{1}$ and a right superior scotoma or quadrantanopia. ${ }^{34}$ While a complete right hemianopia often occurs with pure alexia, ${ }^{3}$ it cannot co-exist with right hemiachromatopsia. ${ }^{12}$ Classical doctrine invariably had pure alexia accompanied by a complete 
Table Clinical features in pure alexia with right hemiachromatopsia (PARH)

\begin{tabular}{|c|c|c|c|c|c|}
\hline Author(s) & Patient age/Sex/Case & Visual fields & Associated Deficits & Aetiology & $\begin{array}{l}\text { Known/Presumed Anatomic } \\
\text { involvement }\end{array}$ \\
\hline Dejerine (1892) & $/ \mathrm{M}$ & Normal & None & Vascular & $\begin{array}{l}\text { Fusiform and lingual gyri, } \\
\text { paraventricular white matter of } \\
\text { left occipital lobe (Autopsy) }\end{array}$ \\
\hline $\begin{array}{l}\text { Shuttleworth, Syring and } \\
\text { Allen (1982) }\end{array}$ & $70 / \mathrm{M} / \# 1$ & $\begin{array}{l}\text { Left homonymous } \\
\text { hemianopia }\end{array}$ & $\begin{array}{l}\text { Partially resolved } \\
\text { prosopagnosia, visual object } \\
\text { agnosia, topographic } \\
\text { disorientation, transient alexia }\end{array}$ & Vascular & $\begin{array}{l}\text { Bilateral occipito-temporal } \\
\text { cortex (EEG) }\end{array}$ \\
\hline \multirow[t]{3}{*}{$\begin{array}{l}\text { Damasio and Damasio } \\
\text { (1983) }\end{array}$} & $14 / \mathrm{M} / \# 1$ & $\begin{array}{l}\text { Right superior } \\
\text { quadrantanopia }\end{array}$ & 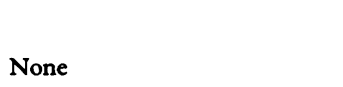 & Vascular & $\begin{array}{l}\text { Fusiform and lingual gyri, } \\
\text { paraventricular white matter of } \\
\text { left occipital lobe (CT) }\end{array}$ \\
\hline & $66 / \mathrm{M} \# \# 2$ & $\begin{array}{l}\text { Right superior } \\
\text { quadrantanopia }\end{array}$ & None & Vascular & $\begin{array}{l}\text { Fusiform and lingual gyri, } \\
\text { paraventricular white matter of } \\
\text { left occipital lobe (CT) }\end{array}$ \\
\hline & $71 / \mathrm{M} / \# 3$ & $\begin{array}{l}\text { Right superior } \\
\text { quadrantanopia }\end{array}$ & None & Vascular & $\begin{array}{l}\text { Fusiform and lingual gyri, } \\
\text { paraventricular white matter of } \\
\text { left occipital lobe (CT) }\end{array}$ \\
\hline Freedman and Costa & $66 / F$ & Normal & $\begin{array}{l}\text { Prosopagnosia, visual object } \\
\text { agnosia (2D), environmental } \\
\text { agnosia }\end{array}$ & $\begin{array}{l}\text { Posterior cortical } \\
\text { dementia }\end{array}$ & $\begin{array}{l}\text { ?Bilateral mesiolateral occipital } \\
\text { cortex }\end{array}$ \\
\hline
\end{tabular}

right hemianopia ${ }^{3}$ although this is no longer accepted in view of numerous reports of alexia occurring without hemianopia. ${ }^{1-3}$ When a partial right VF defect occurs with right hemiachromatopsia, it is almost invariably a superior scotoma or quadrantanopia. ${ }^{4}$ This association results from the anatomical contiguity between the lingual and fusiform gyri and inferior lip of the calcarine sulcus, the area responsible for processing visual stimuli originating from the superior aspect of the VF. ${ }^{4}$ Prosopagnosia, environmental agnosia, and a left VF defect can co-occur with PARH following bioccipital damage, although the right hemisphere lesions do not contribute to PARH. In some instances of bioccipital damage, bilateral achromatopsia occurs. ${ }^{4}$ In our case, PARH was accompanied by prosopagnosia, 2-D object agnosia, and environmental agnosia without a right VF defect or extinction.

Pure alexia occurring simultaneously with right hemiachromatopsia is rare. Including the present case, a review of the literature indexed a total of six cases of PARH $^{167}$ (table). The clinical features of PARH shows that two (33\%) had accompanying prosopagnosia, object agnosia, and environmental agnosia. Right VF function was normal in three cases $(50 \%)$, with the remaining presenting with right superior quadrantanopia. The alexia in one case was transient. The aetiology in five $(83 \%)$ cases was vascular, secondary to infarction in the left posterior cerebral artery (one case $^{7}$ had bilateral PCA infarctions).

The aetiology of PARH in our patient is presumably a focal degenerative disorder maximally affecting the posterior cortices. This posterior cortical dementia (PCD) has been previously described in a number of cases. ${ }^{8}$ While all previously documented cases of PCD had alexia, none had accompanying right hemiachromatopsia, although several had visual extinction. ${ }^{89}$ The aetiology of achromatopsia is predominantly vascular, ${ }^{4}$ and we believe that our case represents the first instance of achromatopsia occurring in an idiopathic dementia.

The anatomy of PARH was uncovered by necropsy examination of Dejerine's patient ${ }^{126}$ which revealed involvement of the paraven- tricular white matter and the lingual and fusiform gyri of the left occipital cortex. Damasio and Damasio, ${ }^{1}$ using CT, re-established the critical importance of damage to the paraventricular white matter and lingual and fusiform gyri in the development of PARH. While our patient had no focal lesions or posterior atrophy on CT, a study using positron emission tomography (PET) in another patient with PCD documented maximal hypometabolism in the mediolateral aspect of the left occipital lobe, ${ }^{8}$ roughly corresponding to the paraventricular white matter and lingual and fusiform gyri.

Experimental studies using both humans and monkeys have demonstrated functional specialisation within the visual cortex with respect to colour and letter processing. $\mathrm{Zeki}^{4}$ has identified a select group of neurons specialied for processing colour that are localised to area V4 of the macaque. PET studies in humans revealed selective activation in the lingual and fusiform gyri to multicoloured, but not achromatic (grey), displays. ${ }^{10}$ Together with clinical data, ${ }^{12}$ these experimental results further support the existence of a colour region in humans localised to the lingual and fusiform gyri which is a homologue of area V4 in the macaque. Similarly, with respect to reading, selective activation in the extrastriate visual cortex (area 18) to letter strings or "visual word forms" has been indexed by PET ${ }^{11}$ in humans, while a pattern of impaired and improved metabolic activity in the left occipital lobe has been reported following the onset and subsequent resolution of pure alexia. ${ }^{12}$

1 Damasio AR, Damasio $H$. The anatomical basis of pure alexia. Neurology 1983;33:1573-83.

2 Damasio AR, Damasio H. Hemianopia, hemiachromatopsia, and the mechanisms of alexia. Cortex 1986;22:161-9.

3 Benson DF. Alexia. In: Frederiks JAM, ed. Handbook of Clinical Neurology, Vol 1 (45). Clinical neuropsychology. Holland: Elsevier 1985;433-55.

4 Zeki S. A century of cerebral achromatopsia. Brain 1990;113:1721-77.

5 Albert ML, Reches A, Silverberg R. Hemianopic colour blindness. ff Neurol Neurosurg Psychiatry 1975;38: 546-9.

6 Dejerine J . Contribution a l'etude anatomo-pathologique et clinique des differences varietes de cecite verbale. Memoires Societe Biologique 1892;4:61-90.

7 Shuttleworth EC, Syring V, Allen N. Further observations on the nature of prosopagnosia. Brain Cogn 1982: 
1:307-22.

8 Freedman L, Selchen DH, Black SE, Kaplan R, Garnett ES, Nahmias C. Posterior cortical dementia with alexia: neurobehavioural, MRI, and PET findings. $f$ Neurol Neurosurg Psychiatry 1991;54:443-8.

9 Benson DF, Davis JR, Synder BD. Posterior cortical atrophy. Arch Neurol 1988;45:789-93.

10 Lueck CJ, Zeki S, Friston KJ, Deiber M-P, Cope P, Cunningham VJ, Lammertsma AA, Kennard C, Frack- owiak RSJ. The colour centre in the cerebral cortex of man. Nature 1989;340:386-9.

11 Posner MI, Petersen SE, Fox PT, Raichle ME. Localization of cognitive operations in the human brain. Science 1988;240:1627-31

12 Silver FL, Chawluk JB, Bosley TM, Rosen M, Dann R, Sergott RC, Alavi A, Reivich M. Resolving metabolic abnormalities in a case of pure alexia. Neurology 1988;38:730-5. 